\title{
UMA ANÁLISE DAS CONTRIBUIÇÕES DE THORSTEIN VEBLEN A PARTIR DA INFLUÊNCIA DA FILOSOFIA PRAGMÁTICA
}

\author{
Fernando Krauzer ${ }^{1}$ \\ Júlio Eduardo Rohenkohl ${ }^{2}$
}

\begin{abstract}
RESUMO
Este trabalho visa apresentar algumas da contribuições de Thorstein Veblen - fundador do institucionalismo original -. O caminho de investigação resgata as influências absorvidas por Veblen e pautadas na incipiência da psicologia para, posteriormente, explicitar aportes teóricos do autor no que se refere ao processo de criação de instituições e o seu processo evolutivo. Com este procedimento coloca-se em relevo a proposta epistêmica e metodológica de Veblen. Considera-se que o institucionalismo original pode contribuir significativamente para o entendimento das instituições na Organização Industrial. Para tal, salienta-se a importância de se atentar à elementos teóricos de Veblen, como por exemplo, os instintos e os hábitos, e o seu papel no direcionamento e condução do comportamento humano. Entre as contribuições veblenianas estão uma definição clara de instituições, uma teoria de constituição de instituições e uma explicação para o conservadorismo socioeconômico.
\end{abstract}

\section{PALAVRAS-CHAVE}

Thorstein Veblen; Instituições; Filosofia Pragmática, Evolução

\begin{abstract}
ABASTRACT
This work aims to present some of the contributions of Thorstein Veblen - founder of the original institutionalism -. The path of research rescues the influences absorbed by Veblen and based on the incipience of psychology to later explain the author's theoretical contributions regarding the process of institution building and its evolutionary process. With this procedure the epistemic and methodological proposal of Veblen is highlighted. It is considered that the original institutionalism can contribute significantly to the understanding of the institutions in the Industrial Organization. For this, it is important to take into account the theoretical elements of Veblen, such as instincts and habits, and their role in directing and conducting human behavior. Among the Veblenian contributions are a clear definition of institutions, a theory of institution building, and an explanation for socioeconomic conservatism.
\end{abstract}

\section{KEYWORDS}

Thorstein Veblen; Institutions; Industrial Organization

\footnotetext{
${ }^{1}$ Mestrando pelo Programa de Pós-Graduação em Economia e Desenvolvimento da Universidade Federal de Santa Maria (PPGE\&D/UFSM).

${ }^{2}$ Professor do Departamento de Economia e Relações Internacionais da Universidade Federal de Santa Maria (DERI/UFSM)
} 


\section{INTRODUÇÃO}

Investigações em Organização Industrial dialogam com o plano institucional das relações socioeconômicas. Um exemplo bem sucedido é a teoria dos Sistemas de Inovação em sua chamada "versão ampla". Este aporte teórico tem aplicações ao nível setorial, local ou nacional, e implica que a capacidade de inovação decorre da infraestrutura de ciência e tecnologia e de um conjunto de instituições e de políticas promovidas por organizações voltadas ao desenvolvimento, ou seja, à mudança estrutural de um sistema econômico ou de parcelas do mesmo, por meio de configurações produtivas e institucionais promotoras de inovações tecnológicas.

Em sua obra sobre o desenvolvimento japonês, Freeman identificou a combinação de esforços das organizações empresariais e das de pesquisas, do sistema educacional e das políticas públicas que concorreram para a promoção de inovação e de sua difusão por aquele sistema econômico. A visão ampla de sistema de inovação abarca a atenção à história e à cultura locais na medida em que contribuem para a estruturação e evolução produtiva (Freeman, 1987; Szapiro et al., 2017).

Outros temas de dinâmica industrial também têm a ganhar com a incorporação do olhar institucional. Uma questão importante que tem nas instituições um contributo explicativo potencial é a formação de preços por meio de mark-up, conforme formulação derivada de pesquisa empírica por Hall e Hitch ([1939]1986). Aquele estudo verificou que vários setores industriais oligopolizados formavam preços mediante $o$ estabelecimento de margens convencionais sobre o custo variável médio de produção para remunerarem os custos indiretos e os lucros. Isto implicava uma estabilidade dos preços de venda por longos períodos. A teoria careceu de explicação sobre o processo de estabelecimento inicial deste preço focal. Os autores argumentaram que isto estaria inscrito na história do ramo industrial. A formação de preços por mark-up requer o complemento de uma história institucional industrial.

Os estudos industriais ganham em consistência caso combinem informações da demanda. As tentativas de compreender comportamentos de consumo, tais como as de Witt (2001, 2016) também têm na compreensão de processos de aprendizagem institucionalizado uma contribuição para seu aprofundamento. O consumo é interpretado por Witt (2001) como o dispêndio de dinheiro para obter o comando sobre uma mercadoria. A questão fundamental é estabelecer como surge o desejo de comandar a mercadoria. $\mathrm{O}$ institucionalismo investiga as propensões habituais a agir.

Como tantas outras noções disseminadas pela economia, "instituição" não é um termo de definição única e precisa. Isto decorre das variações conceituais, teóricas e epistemológicas, nada triviais, existentes entre os cientistas sociais que dedicam atenção especializada às instituições. O objetivo deste artigo é apresentar elementos importantes da construção teórica de Thorstein Veblen, principal autor do institucionalismo original. É bem conhecida a sintonia de Veblen com a transformação tecnológica da vida material, fato que o aproxima das correntes de Organização Industrial voltadas à evolução econômica desencadeada por inovações. No entanto, acredita-se que o potencial de fertilização teórica decorrente das ideias veblenianas seja ainda mais amplo e possa render avanços em tópicos como o estabelecimento de padrões de formação de preços, padrões de concorrência setoriais, de aprendizagem de consumo especializado, entre outros.

Salienta-se que são conhecidas as contribuições contemporâneas a respeito do tema, tanto nacionalmente quanto internacionalmente ${ }^{3}$. Porém, zelando pelo

\footnotetext{
${ }^{3}$ Nota-se alguns nomes predominantes no estudo contemporâneo da economia institucional, como por exemplo: Hodgson (2004), Almeida (2016; 2014), Dequech (2003).
} 
entendimento original das contribuições de Thorstein Veblen, opta-se na utilização e análise das obras primarias do autor e seus comentadores. Essa escolha justifica-se frente ao objetivo central deste trabalho que visa à composição de influências no escrito deste institucionalista. Desse modo, é mister que sejam entendidas suas obras em seus anseios e objetivos originários. Esse recorte bibliográfico não empobrece a discussão aqui almejada, pelo contrário, a direciona ao que aqui é objetivado. Sendo assim, são entendidas e respeitadas as contribuições posteriores baseadas nos estudos de Veblen, mas aqui não se as tem em enfoque.

Desse modo, zelando pela viabilidade deste trabalho, o mesmo é dividido em três partes: primeiramente (i) apresenta-se o posicionamento epistêmico e metodológico de Veblen, seguido da (ii) apresentação das influências da filosofia/psicologia pragmática na obra do autor, passando, logo após, a (iii) discutir a construção teórica e a evolução institucional a partir de hábitos e instintos.

\section{THOSRSTEIN VEBLEN: ENTENDENDO SUA PROPOSTA TEÓRICA}

A leitura atenta dos trabalhos de Veblen levam o seu leitor aos mais diferentes campos do conhecimento humano. Além da teoria econômica, também é possível identificar nos trabalhos de Veblen traços de análise social e histórica, da psicologia e da antropologia, sendo que cada um desses campos é normalmente apresentado e trabalhado através de comentários políticos tidos como radicais, bem como através de sátiras e ironias. Tal constatação é evidenciada e trabalhada por diversas obras de diversos autores, como por exemplo, em Essential Writings of Thorstein Veblen (2011), de Charles Camic e Geoffrey Hodgson. Neste livro os autores visam à contextualização intelectual de Veblen, através da seleção de obras tidas como essenciais para o entendimento da teoria econômica e das críticas que Thorstein desenvolvera ao longo de sua carreira.

Com base nesta obra, podemos observar que as contribuições de Veblen, apesar de tidas como ricas e multidimensionais, não receberam a projeção como de outros grandes pensadores da economia de seu século, como por exemplo, Keynes e Hayek. Segundo os autores, esse fato deve-se ao caráter não primordial que Veblen teria dado a questões como filosofia moral e desenvolvimento de políticas. Afinal, tais características foram de grande repercussão na ciência economia desde sua fundação e ao longo de todo o século XIX e XX. Diferente disso, Veblen atuou no pensamento econômico em tom de crítica ao modo de se fazer a essa ciência (Camic \& Hodgson, 2011).

As críticas de Veblen constituíram-se da apresentação a uma nova forma epistêmica. Através delas, Veblen apresenta uma via alternativa à teoria econômica através de um paradigma darwiniano regido, analisado e interpretado através de noções da filosofia e da incipiente psicologia. Fica evidente o caráter psicológico-filosófico de Veblen ao longo de todos os seus escritos, pois suas reflexões mostram-se extremamente complexas, sendo necessário o domínio das mais diversas referências destas áreas do conhecimento para que sejam entendidas suas críticas e contribuições ao pensamento econômico. Desse modo, Camic \& Hodgson (2011) apontam que dentre as mais diversas inspirações de Veblen as que se destacam são: a filosofia pragmática clássica e as noções psicológicas ligadas a esta escola filosófica pautada nos escritos de Charles Sanders Peirce, John Dewey e William James, principalmente no que se refere a noção de hábitos, instintos e instituições; e, por fim, como consolidador destas influências, os princípios evolucionários baseados em Charles Darwin. 
Outros autores convergem com estes destaques, dentre eles Rutherford (2011), Cavalieri (2009), Monastério (1998) e Hamilton (1970). Sendo que Rutherford (2011) pontua a abordagem evolucionária de Veblen baseada na causa eficiente, o que vem a municiar uma série de críticas ao escritos Neoclássicos por parte de Veblen. Em Cavalieri (2009) vemos outra vez menção as importantes influências do pragmatismo clássico e suas lições psicologistas somado a noções darwinianas, enquanto o autor tenta situar Veblen em seu tempo e lugar. Em Monastério (1998) também fica evidente o caráter evolucionário da teoria vebleniana quando o autor faz menção e desenvolve a importância dos hábitos nos escritos do institucionalista. E, na tese de $\mathrm{PhD}$ de David Hamilton, intitulada Evolutionray Economics: A Study of Change in Economic Thought, de 1970, elementos darwinianos e pragmáticos também são observados em relação aos trabalhos Thorstein Veblen, sendo que Hamilton atua num sentido de contrastar tais influências com os escritos de origem não evolucionária na economia.

Hamilton (1970) observa que o darwinismo atuou de maneira influente em boa parte da academia norte-americana do fim do século XIX e início do século XX. Porém, mesmo oriundo de uma única inspiração, diversas formas de manifestação puderam ser vislumbradas. Segundo o autor, de um lado puderam ser observadas interpretações de Darwin como "prova" de uma ordem natural competitiva que atuaria através de um "livre mercado" . De outro lado houveram interpretações mais consistentes e coerentes de Darwin, em que a análise de processo de mudança se torna crucial. Sendo que sobre este segundo grupo Hamilton (1970, p.25) se faz bastante claro, argumentando que "no one saw the significance of the Darwinian revolution on social thought more clearly than did Veblen".

Ainda segundo Hamilton (1970), nota-se que a influência darwiniana atuou de maneira muito bem colocada pelos eventos históricos. Afinal, via-se constantes e rápidas mudanças socioeconômicas acontecendo tanto na Europa quanto nos EUA, principalmente pós revolução industrial. Cada vez mais, observar a esses fenômenos de maneira estática numa ótica de causa e efeito se fazia ineficaz e inadequado, pois era necessário que também fossem atentados e entendidos os processos de mudança, fazendo claro "como" e "por que" ocorriam. Exatamente esse foi o papel das noções darwinianas no pensamento econômico de Veblen e seus seguidores (Hamilton, 1970).

Desse modo, observa-se que esse novo caráter epistêmico atribuído a Veblen através de um paradigma darwiniano fez com que esse autor fosse apto a desenvolver uma teoria evolucionária no que diz respeito a análise do comportamento econômico e social. Importantes conceitos da teoria Vebleniana foram desenvolvidos e trabalhados devido a este importante caráter paradigmático, como por exemplo, os hábitos de pensamentos, os instintos, as instituições, e como estes evoluem em um contexto de coexistência exercendo influência de forma multidimensional entre si. Desse modo, fica mais do que evidente a importância de entendermos como se deu e a que exatamente se referia à influência evolucionária em Veblen.

Why Is Economics Not an Evolutionary Science? (1898), foi, provavelmente, onde Veblen melhor apresentou e formalizou suas críticas em relação à economia de sua época e por que, na opinião dele, esta ciência estava defasada em relação a outras áreas do conhecimento. Nesta obra, Veblen destaca a primordial importância de se manter atrelados os conhecimentos de ordem social, delatando a desconexão dos avanços teóricos em campos como a antropologia, etnologia e psicologia em relação à ciência econômica. Para Veblen, tal desconexão seria resultado de um atraso no modo de se

\footnotetext{
${ }^{4}$ Nesta leitura, em específico, Hamilton (1970) se refere aos trabalhos de William Graham Sumner. Acredito que neste primeiro grupo possam ser inseridos também os trabalhos de Herbert Spencer. Ambos os autores são entendidos hoje como colaboradores da teorização de um Darwinismo Social.
} 
fazer a ciência econômica (Veblen, 1898) ${ }^{5}$. E, assim como o título do trabalho antecipa, o atraso qual Veblen se refere está associado a questão: "por que a economia não é uma ciência evolucionária?".

Veblen (1898) aponta que, mesmo que estivessem em busca de uma abordagem moderna para suas teorias, os economistas contemporâneos a ele continuavam a perpetuar equívocos metodológicos de inspirações naturalistas ligados a noções utilitaristas e teleológicas. Ao reconhecer tal característica no pensamento econômico de sua época, Veblen argumenta que esses seriam reflexos de antigos ensinamentos desta ciência que estariam, de maneira anacrônica, sendo perpetuados ${ }^{6}$. Desse modo, para Veblen, uma ciência moderna deveria apresentar características evolucionárias, sendo que "any evolutionary science [...] is a close-knit body of theory. It is a theory of a process, of an unfolding sequence" (Veblen, 1898, p. 375).

Entender processo de mudança implica, como Veblen (1898) bem pontua, analisar relações causais. Para tal, é necessário que se abdique de noções mecanicistas de causa e efeito oriundas de estática comparativa. Veblen (1898) mostra que, somente no primeiro caso, torna-se viável a construção de teorias que compreendem os processos através uma noção de causação cumulativa. Para o autor, as noções de leis naturais estão diretamente relacionadas às noções de sequências mecânicas. Segundo Veblen (1898), quando se assumem as leis naturais, todos os demais fatores de causação são tidos como fatores de distúrbio para qualquer corpo de conhecimento não evolucionário. Tal noção metodológico-teórica seria uma herança dos escritos clássicos que deveria ser superada (Veblen, 1898).

É valido lembrarmos que essa percepção de objetos de estudo é entendida por Veblen (1898) como resultado dos hábitos de pensamento arcaicos presentes no modo de se pensar a ciência moderna (pós-darwiniana). Veblen (1898) estabelece papel fundamental dos hábitos no processo de desenvolvimento da ciência. Ou seja, Veblen analisou a ciência econômica do mesmo modo que analisou qualquer outro grupo e/ou coletividade, entendendo seus hábitos de vida e de pensar de acordo com aquilo que já fora lá construído e instituído anteriormente.

É importante observar que Veblen via o processo de habituação como algo que atinge aos indivíduos como um todo, e não apenas a uma faceta de sua personalidade (Monasterio, 1998). Desse modo, em alguma medida, Veblen destaca as mudanças habituais como correlatas com a nossa realidade material, atribuindo fundamental importância da lógica industrial moderna à necessidade de mudança no discurso econômico. Nesse mesmo sentido, Veblen distancia-se das noções do positivismo lógico quantitativo-empirista que atribui imparcialidade aos fatos. Afinal, na noção vebleniana, os fatos são observados no contexto dos hábitos de pensamento e na teoria científica que estão naquele momento sendo compartilhados e executados. Ou, pelas palavras de Monastério (1998, p.25):

Os hábitos de pensamento têm um papel cognitivo que se mostra presente na forma com que os fatos pertinentes à construção do conhecimento científico são apreendidos. O principio do positivismo lógico de que os fatos falam por si é, portanto, negado por Veblen. Os

\footnotetext{
${ }^{5}$ Cabe destaque que Veblen analisou a ciência econômica como analisou toda e qualquer outra forma coletiva de organização. Isso implica reconhecer a existência de hábitos de pensamento que são compartilhados pelos agentes dessa organização, justificando um efeito inercial de aversão à mudança.

${ }^{6}$ Veblen admite que na Escola Histórica Alemã houve significativo avanço no modo de se fazer a ciência econômica. Porém, mesmo frente aos avanços que esta escola pode almejar, fora perceptível severa carência teórica.
} 
fatos são sempre observados no contexto dos hábitos de pensamento e da teoria científica vigentes.

Sobre o aspecto correlato entre realidade material e habituações, Veblen destaca que as noções pré-evolucionárias estão diretamente relacionadas com o estilo de vida pré-industrial da antiga manufatura, onde se observava uma lógica científica e produtiva que atentava à causalidade, porém somente em termos de causa e efeito que, por sua vez, estavam fortemente ligados a noções animistas e teleológicas. Em mesmo sentido, numa sociedade industrial moderna, as noções produtivas relacionadas a processo de causalidade cumulativa (como numa indústria em série, por exemplo) se fazem cada vez mais habituais na vida nos indivíduos assumindo, muitas vezes, uma nova lógica de raciocínio (Veblen, [1914] 2006).

Veblen (1898) ainda identifica duas características intimamente relacionadas ao modo pré-evolucionário de se fazer a ciência econômica, que seriam a (i) ênfase na teleologia, principalmente através da "identificação" e aceitação da presença de leis naturais no comportamento humano e social; e a (ii) ênfase na taxonomia, com objetivo de devidamente classificar e definir os objetos de estudo através da criação de terminologias técnicas para os fenômenos econômicos. Sobre essa segunda ênfase apresentada, Monastério (1998) aponta que em alguma medida esse seria um fator a se considerar positivo no modo de se fazer a ciência pré-evolucionária, pois criara um sistema taxonômico útil que pode ser usado como ponto de partida para uma ciência pós-darwiniana, ou em melhores termos, evolucionária, conforme sugerida e almejada por Veblen.

Desse modo, podemos observar que Veblen estabelece uma relação causal entre os hábitos de vida e os hábitos de pensamento. Afinal, a realidade material afeta o modo de pensar e o desenvolvimento científico dos indivíduos. Ainda sobre isso, Veblen ([1914] 2006) aponta que, conforme a nova lógica industrial se insere na vida moderna, os novos hábitos de pensamento também começam a apresentar-se no modo de se fazer a ciência. E, conforme já destacado, relações de causa e efeito (situações iniciais e situações finais) começam a perder sentido no complexo processo de causação cumulativa.

Visando a sumarização da construção epistêmica e metodológica de Veblen, podemos observar que seu principal ponto estava na insatisfação para com as respostas oriundas da ciência econômica contemporânea a seu tempo. Sobre isso, e com precisão de palavras, Cavalieri (2009, p.303) destaca:

Em suma, Thorstein Veblen não propôs um sistema científico baseado numa metodologia compreensiva, à moda de Max Weber (18641920), mas sim uma explícita metodologia explicativa, assim como ele entendeu a metodologia dos clássicos, neoclássicos e marxistas. Seu intento era mostrar a insuficiência destas teorias pelo pecado de teleologia e, questionar se não existiriam questões mais profundas a serem formuladas a partir de princípios científicos pós-darwinistas. "Abrir a caixa-preta da economia neoclássica", "dar um passo atrás" e colocar a questão sobre como se formam os comportamentos humanos não implicam necessariamente propor uma ciência hermenêutica, sem intenções generalizantes. Alias, muito pelo contrário, o sistema vebleniano pretende-se muito mais geral do que as economias prédarwinianas.

Tendo em vista toda a construção deste aspecto metodológico na teoria vebleniana, ainda cabe destaque ao caráter que se compõe como evolucionário nesse arcabouço teórico. Sobre isso, Veblen (1900) destaca o papel fundamental das 
instituições no processo de evolução socioeconômica. Afinal, na perspectiva vebleniana, as instituições seriam composições de hábitos de vida e de pensamento que são socialmente compartilhados. Esses hábitos por sua vez, seriam resultados das sequências cumulativas da vivência e da cultura dos indivíduos. Nesse sentido, então, para Veblen (1900) a economia evolucionária deveria estar sujeita a conduta humana e sua sequência cumulativa de causalidade que se apresenta através dos hábitos e das convenções sociais que são institucionalizados.

Ou seja, fica evidente que, para que possamos melhor entender as contribuições e críticas de Thorstein Veblen, devemos direcionar nossa atenção para a construção e noções dos importantes conceitos de hábitos, instintos e instituições. Porém, esses são constituídos e apresentados na teoria vebleniana com base em uma importante influência desse pensador. A filosofia pragmática clássica através de suas noções psicologistas, majoritariamente de John Dewey.

\section{A INFLUÊNCIA DA FILOSOFIA PRAGMÁTICA CLÁSSICA: O PAPEL DE JOHN DEWEY NA TEORIA DE VEBLEN}

É importante notarmos que para Veblen o comportamento humano não é atrelado somente a uma nascente, seja ela coletivista ou individualista, determinista ou não. Essa perspectiva faz-se presente e, provavelmente, melhor entendida em The Theory of The Leisure Class (1899) uma das obras em que o autor melhor trabalha suas noções psicologistas e sociológicas a respeito do individuo e do comportamento social (Almeida, 2015a). Nesta obra, Veblen interpreta o individuo como um ser envolto em uma rede de influências socioeconômicas e culturais, porém também apresenta capacidade de interferência nessa rede. Desse modo, na perspectiva de Veblen, não há uma determinação única no comportamento do indivíduo, mas sim uma multidimensionalidade de causas e efeitos que se dão através de relações causais cumulativas entre o indivíduo e seu ambiente. Ou seja, nota-se a presença de uma característica holística junto aos trabalhos de Veblen.

Nesse ponto torna-se evidente a influência pragmática contida nos escritos do autor, afinal essa escola filosófica surge com o objetivo de entender os desdobramentos dos fatos através da limitação das especulações visando um pensamento e resultado mais eficientemente possíveis (James, [1922] 2009). Desse modo, fugia de aspectos morais que antes eram fortemente atrelados a questões filosóficas e que, por muitas vezes, levavam as reflexões a um nível interminável de complexidade ineficiente. Ou seja, o pragmatismo, assim como o nome já nos delata, surgiu com o objetivo de tornar as discussões filosóficas que antes eram de cunho abstrato, em práticas. Isso se objetivou, principalmente através da noção de que o conhecimento e o pensar são os mecanismos e os instrumentos para se obter as respostas, e não as respostas em si (James, [1922] 2009).

É importante que também seja destacado o fato de o pragmatismo clássico ter sido a primeira escola filosófica pós-darwiniana (Webb, 2007). Esse fato é fundamental de se atentar tendo em vista o método de analise e pesquisa dessa escola que, como veremos pautou-se no entendimento dos padrões de comportamento do individuo frente ao cenário em que este está inserido. Também é importante observarmos que há grande síncrono entre o pensamento da filosofia pragmática clássica com os estudos incipientes da psicologia, muitas vezes fazendo com que essas perspectivas teóricas atuassem como 
complementares, como bem destaca Landsman (1957) em The Philosophy of Veblen's Economics ${ }^{7}$.

O primeiro contato de Veblen com o pragmatismo clássico se deu através de seu mestre Charles Sanders Peirce na Universidade de John Hopkins ${ }^{8}$ (Landsman, 1957). Após este primeiro contato, Veblen desenvolveu o trabalho intitulado Kant's Critique of Judgment (1884), em que busca associar a construção científica de Kant com a filosofia de Charles Peirce. Com base nesse trabalho é possível notar a identificação da influência de hábitos mentais no comportamento dos indivíduos, baseado na noção de princípio-guia (guiding principle) de Peirce (Daugert, 1950 apud Monastério, 1998). Landsman (1957), apesar de designar à Peirce a introdução de Veblen à filosofia pragmática, pontua que esse não foi o seu principal influenciador. Esse papel, Landsman (1957), atribui a outro grande pensador da escola pragmática, John Dewey (1859-1952), que fora colega de Veblen durante sua estadia profissional na Universidade de Chicago, e atuou na ampliação e divulgação de importantes noções e ideias relacionadas ao pragmatismo e sua nascente psicologista. Landsman (1957) também pontua a importante contribuição de William James (1842-1910) para a construção teórica de Veblen. Segundo o autor, pode ser atribuído a James o papel de maior idealizador e divulgador das noções psicologistas do período, atuando tanto como pragmatista quanto psicologista, buscando desenvolver uma nova teoria psicológica que unia os princípios darwinianos, a filosofia pragmática e as ciências naturais (Landsman, 1957).

É importante se comentar que ao atrelar a filosofia pragmática com suas noções psicologistas, Veblen pôde cunhar seu propósito evolucionário no âmago de sua teoria. Com base nessa conexão Veblen apropriou-se de noções evolutivas no contexto social e histórico, viabilizando uma nova percepção dos objetos de estudos relacionados à ciência econômica. Afinal, observar aos indivíduos como resultado cumulativo de mudança atentando a fatores psicológicos e antropológicos permitiu não só uma nova construção teórica, mas também um novo caráter epistêmico sobre como se construir uma ciência econômica numa perspectiva industrial (moderna) ${ }^{9}$ (Landsman, 1957).

Em The Origins of Thorstein Veblen's Thought (1979), de William Dugger, também são esboçadas algumas das principais influências que vieram a originar o pensamento de Veblen. Assim como Ladsman (1957), Dugger também atribui fundamental importância à Dewey. Segundo o autor, uma das principais influências de Dewey em Veblen se dá na percepção de que as ciências sociais deveriam estar livres de verdades absolutas (Dugger, 1979). Afinal, através da noção pragmática, as verdades absolutas eram interpretadas como uma criação teleológica manifestada pela vontade de uma entidade superior (divindade antropomórfica). Já a verdade pragmática poderia ser entendida como algo mais mundano, que representaria a vontade dos homens em seu

\footnotetext{
7 Em algumas passagens, Landsman (1957) se refere aos vieses psicológicos como "psicologia pragmática". Com isso o autor frisa que esta seria uma noção psicologista atrelada fortemente à filosofia pragmática. Contemporaneamente, os escritos pragmatistas a respeito da psicologia apresentam-se em diferentes abordagens psicológicas, como por exemplo, a Psicologia Social e a Psicologia Behaviorista (ou comportamentalista).

${ }^{8}$ Landsman (1957) pontua que Peirce fora o fundador desta escola filosófica e, este nome (pragmatismo) teria sido oriundo do termo "pragmatisch" retirado de Critique of Pure Reason de Immanuel Kant. Tal influência teria sido reconhecida pelo próprio Peirce e, provavelmente teria sido uma das influências para o trabalho que Veblen desenvolveria posteriormente na tentativa de convergência entre estes dois autores.

${ }^{9}$ Foi também sobre o crivo pragmático-evolucionário que Veblen conseguiu distinguir-se de outras teorias atreladas a noções historicistas, principalmente desviando de tendências positivistas ou então deterministas. Afinal, conforme já observamos anteriormente, o processo evolutivo não permite previsibilidade do futuro, nem mesmo juízo de valor.
} 
contexto de valores. Tanto Dewey quanto Veblen partilhavam dessa noção, mesmo que em seus interesses primários estivessem atentando a aspectos teóricos diferentes, sendo que Dewey focava em políticas sociais enquanto que Veblen focava em evolução social (Dugger, 1979).

Dentre outros aspectos oriundos da influência pragmática-psicologista em Veblen, fica evidente o entendimento de que os indivíduos são agentes ativos em relação às condições que os rodeiam (Camic \& Hodgson, 2011). Essa perspectiva rompe com uma das grandes tradições do pensamento econômico baseada na noção de "prazer" ou "dor" da filosofia utilitarista. Através do reconhecimento das diferentes influências existentes entre individuo e meio, torna-se possível a observação e o entendimento de importantes relações causais. Tal reconhecimento evidencia o caráter pós-darwiniano da filosofia pragmática, bem como sua conexão com aspectos de ordem psicológica. E, é exatamente nesse ponto que surge a complementariedade com os escritos psicologistas, principalmente de John Dewey, na teoria vebleniana. Afinal, Veblen baseia-se, majoritariamente, nesse autor quando busca entender aos hábitos de pensamentos dos indivíduos, bem como seus instintos e sua capacidade de organização social através das instituições socioeconômicas (Veblen, [1914] 2006). Essa influência está diretamente relacionada aos interesses de Veblen em convergir áreas do conhecimento que são complementares ao se entender o comportamento humano e as relações sociais. Tal objetivo também se faz presente na filosofia pragmática, o que lhe confere papel de destaque no desenvolvimento da psicologia.

\subsection{John Dewey: hábitos e comportamento}

Conforme já mencionado, vários autores convergem para o papel de destaque da influência de Dewey na teoria de Veblen, principalmente no que se refere ao conceito de hábitos e a perspectiva evolucionária (Dugger, 1979; Hamilton, 1970; Landsman, 1957; Almeida, 2015a; 2015b). Conforme já destacado anteriormente, tal influência apresenta-se como resultado de uma aproximação de interesses (Landsman, 1957).

Segundo Tilman (1998, p.145), "John Dewey [...] is easily the most influential philosopher America has produced and Thorstein Veblen [...] is arguably the most influential American heterodox economist". Na sequência destes reconhecimentos o autor aponta a presença de influências muito fortes de Dewey nos escritos do institucionalista, porém Tilman comenta que a forma de escrita e a ausência de referências nos trabalhos de Veblen fazem com que seja bastante difícil a identificação precisa destas influências. Sobre essa questão, o autor atenta, então, ao fato de Dewey ter também se utilizado fortemente das ideias de Veblen, todavia com o uso mais fiel de menções e citações. Segundo Tilman (1998), através desta curiosa solução, parte das convergências de ideias entre os autores podem ser melhor identificadas e entendidas.

Fica evidente através de Tilman (1998) o radicalismo presente nas ideias de ambos os autores, principalmente em questões relacionadas à oposição ao status quo. Segundo Dewey ([1934] 1981) o status pode ser visto como o resultado de um histórico de admiração imposta por conceitos institucionalizados. Na perspectiva do filósofo, nestes conceitos nota-se o importante papel atribuído ao consumo de bens e a construção de classificações sociais entre grupos específicos da sociedade, como por exemplo, a distinção entre ricos e pobres (Almeida, 2015b). Ainda mais do que isto, é possível identificar a convergência dos autores em assuntos ainda mais específicos relacionados, por exemplo, a igualdade de gênero, quando Dewey utiliza-se de passagens de The Theory of The Leisure Class e The Theory of The Business Enterprise 
para fundamentar seu argumento em prol de ideias feministas (Tilman, 1998). O autor também salienta que não deve ser subestimado o entendimento de Dewey sobre a ciência econômica. Afinal, assim como Veblen, Dewey também se mostrou um "devorador" ávido de todos os tipos de leituras das mais diversas áreas do conhecimento, em especial, social e humano.

Foi através de Veblen que Dewey fez a diferenciação entre a "economia pecuniária" e a "economia industrial", entendendo o papel e as funções de cada um delas. Sobre a segunda, especificamente, Dewey argumenta que o desenvolvimento industrial moderno poderia ser visto como um fruto resultante do desenvolvimento de importantes aspectos de cunho científico e tecnológico. E, somente através do reconhecimento e fomento desses importantes fatores que poder-se-ia vislumbrar a continuidade do progresso humano e econômico. Desse modo, Dewey, assim como Veblen, dedicava papel importante aos aspectos industriais, científicos e tecnológicos aos louros da sociedade moderna (Tilman, 1998). Ainda segundo Tilman (1998), foi exatamente essa noção de progresso associada ao caráter tecnológico e científico que fez com que Dewey atentasse à importância da educação no desenvolvimento socioeconômico, tornando-o um dos maiores críticos do sistema educacional norteamericano da época. E em mesmo sentido, despertou o interesse do autor para assuntos relacionados ao processo de aprendizagem.

Tendo como temática principal a análise do comportamento e do processo de tomada de decisão, Dewey estabeleceu papel fundamental aos hábitos. Afinal, segundo o autor, todo comportamento seria o resultado de um processo de aprendizado entre os indivíduos e o seu ambiente. Desse modo, haveriam disposições comportamentais que são aprendidas pelos indivíduos, e que por eles podem ser exercidas frente a cenários específicos. Quando constata-se a ausência dessa disposição prévia para algum cenário, o indivíduo então fará uso da observação do comportamento alheio visando encontrar o modelo de comportamento adequado para aquele cenário em específico (Dewey, [1939] 1981).

Com base na noção de habituação de Dewey, fica evidente a característica de aquisição dos comportamentos. Afinal, essa aquisição ocorre frente ao processo de aprendizagem oriundo do convívio entre os indivíduos. Sobre tal, Dewey ([1939] 1981) destaca que o ser humano não é uma criatura de instintos ou razão, mas sim de hábitos. Sendo que, segundo Dewey, no limite de sua definição, os hábitos podem ser vislumbrados através da tendência de repetição de comportamentos aprendidos frente a cenários e estímulos específicos.

Dewey, então, estabelece como fundamental ao caráter observacional dos indivíduos, explicitando, pincipalmente, o papel da experiência neste processo de aprendizagem relacionado à habituação (Dewey, [1934] 1981). Ao apresentar as experiências, Dewey esclarece o processo de aprendizado como uma relação entre memoria e emoções, sendo que através desses fatores, os indivíduos são levados a associações e memorizações. Tendo sido exposto à uma experiência, o indivíduo fara dela uma referência de aprendizado recorrendo aos estímulos e sentimentos gerados por esta, sempre que necessário. Sendo assim, segundo Dewey ([1934] 1981) inicia-se um processo de criação de padrões: "[t]he outline of the common pattern is set by the fact that every experience is the result of interaction between a live creature and some aspect of the world in which he lives" (Dewey, [1934] 1981, p. 562).

Dewey ainda comenta o caráter de fixação e maturação relacionado a essas experiências, salientando que ao ser exposto a uma experiência e tornando-se adepto da mesma em sentimento, memória e consciência, esta apresentará uma característica de permanência em forma de aprendizado. Isso ocorre, pois como Dewey bem comenta, 
todas as experiências integrais apresentam uma conclusão ao final; uma ideia, uma lição. Desse modo, Para que possa ser substituída ou readequada o individuo passará por um processo de reconstrução que, segundo Dewey ([1934] 1981, p. 560) “[...] may be painful". Sendo assim, a experiência, munida de seu caráter habitual, se fará enraizada nos indivíduos que a viveram, tonando não trivial o seu processo de alteração e/ou exclusão.

Neste ponto começa a ficar evidente o caráter psicologista relacionado a filosofia pragmática, principalmente no que se refere ao método. Assim como fica evidente na análise de habituações de Dewey, o caráter psicológico que guia os indivíduos apresenta-se como fundamental no modo de se pensar o comportamento social. Foi neste ponto e com essa inquietação em mente que Dewey defendia a psicologia como um método filosófico (Dewey, [1886] 1981). Com base nesta inquietação, Dewey expressou uma das frases mais célebres sobre o seu posicionamento a respeito das nuances entre os estudos da filosofia e da psicologia: "[...] what else can philosophy in its fullness be but psychology, and psychology but philosophy?" (Dewey, [1886] 1981, p. 127) ${ }^{10}$.

Sobre este ponto, Koschmann (2000) destaca o papel crítico de Dewey ao argumentar que o processo de aprendizagem dos indivíduos mostrava-se muito mais complexo do que como defendido por teorias psicologistas que reduziam esse processo à um "estimulo resposta". Segundo Dewey (1896) o processo cognitivo seria muito mais complexo do que aqueles representados por modelos mecanicistas e reducionistas ${ }^{11}$. Concomitantemente, ao debruçar-se sobre estudos da ciência econômica, Dewey também deixava clara sua insatisfação com os modelos simplistas de bases utilitaristas que visavam desenhar o comportamento humano em uma lógica binária de "utilidade" ou "desutilidade" (Tilman, 1998). Em síncrono a sua crítica, Dewey apresentava seu conceito de "psicologia social" que mostraria como fundamental a relação dos indivíduos e sua socialização através dos hábitos. Desse modo, Dewey estabelece importante relação entre comportamento humano e hábitos, sendo que para o autor, os hábitos atuariam como funções comportamentais ${ }^{12}$ (Koschmann, 2000). Em sentido semelhante, destaca-se também o papel crítico desempenhado por Dewey em relação à escola sociológica francesa, especificamente dos escritos de Durkheim. Pois, segundo Dewey (apud Koschmann, 2000), trata-se de um equivoco conceder a totalidade dos créditos do comportamento humano à realidade material em que o mesmo está inserido. Afinal, há no indivíduo a capacidade de interferência neste processo, em forma de uma relação de força inversa que, por óbvio possui menos intensidade, porém apresenta-se existente (Koschmann, 2000). Esta última passagem também evidencia um caráter holístico nas ideias e teorias de Dewey.

Neste ponto, então, é válido lembrarmos que Dewey não estabelece uma relação determinística no aspecto habitual dos indivíduos, cabendo a estes, o discernimento através de suas capacidades cognitivas e atributos de inteligência, principalmente através das margens das consequências e das responsabilidades por eles julgadas como morais (Koschmann, 2000). Desse modo, a conduta humana é primariamente habitual, mas não é refém desta característica. Sobre os diferentes aprofundamentos habituais,

\footnotetext{
10 Acredito que essa passagem evidencie da melhor maneira o caráter verdadeiramente pragmático empregado por Dewey na sua visão acerca da filosofia. Afinal, observa-se através deste comentário que Dewey fazia uma leitura bastante instrumental e aplicada a respeito do pensamento filosófico.

${ }^{11}$ Esta crítica de Dewey estava diretamente relacionada ao papel que vinha se dando aos chamados "Reflex Arc" nos escritos psicologistas contemporâneos ao seu tempo.

${ }^{12}$ Koschmann (2000) argumenta que como função comportamental, Dewey fazia referência a uma noção biológica e matemática do conceito, em que haveria diferentes combinações de diferentes fatores que gerariam um resultado diferente a cada recombinação.
} 
Dewey destaca a relação direta entre a eficiência de determinado hábito lidar com cenários hodiernos e a sua profundidade no comportamento humano, ou pelas palavras de Dewey (apud Koschmann, 2000, p.317): "The more suavely efficient a habit the more unconsciously it operates".

Ainda sobre o caráter de habituação na perspectiva de Dewey, pode-se observar outras características bastante relevantes, dentre elas, Almeida (2015b) destaca o papel dos hábitos na tomada de decisão gerenciando e direcionando elementos inerentes ao consumidor, entre o indivíduo e o seu ambiente. Essa passagem evidencia-se em Dewey ([1939] 1981; [1934] 1981) quando o autor afirma que os hábitos são destrinchados através das interações entre os elementos dados pelo tomador de decisão, através de uma ótica viesada pelas tradições do mundo externo (ambiente). Sendo assim, pela perspectiva de Dewey, segundo Almeida (2015b, p.12): "[h] abits are the influence of past knowledge on current knowledge in such a manner that the past conditions but does not determine present decision making”.

Finalmente, Dewey ([1939] 1981), também salienta que o caráter habitual dos indivíduos está fortemente associado a sua necessidade de pertencimento e acolhimento com o grupo social de identificação. Visando o pertencimento e o preenchimento social o indivíduo é levado, via experiência, à aceitação e prática dos hábitos institucionalizados por aquele grupo. No caso da sociedade capitalista desenhada por Veblen n'A Teoria da Classe Ociosa, por exemplo, observa-se essa noção através do individuo que é levado a uma emulação pecuniária movida pela manutenção do status quo e a soberania das classes mais abastadas, dado que, vis-à-vis experiências anteriores, essas características representavam o sucesso social.

\section{O PAPEL DOS INSTINTOS, HÁBITOS E INSTITUIÇÕES NA TEORIA VEBLENIANA: O PROCESSO DE EVOLUÇÃO INSTITUCIONAL}

Até aqui pudemos, de maneira sucinta, melhor entender as influências de Dewey na teoria de Veblen. Conforme já destacado no inicio daquela seção, as influências do institucionalista não se esgotam neste autor, sendo possível notar associações do discurso vebleniano com variadas fontes do conhecimento. Sobre isso, Edgell \& Tilman (1989) elencam mais de dez fontes de influências das ideias veblenianas. A saber, o caráter evolucionário de Charles Darwin e a filosofia pragmática clássica com seus estudos incipientes na psicologia representam apenas três destas influências. Ainda assim, como vimos, parece haver grande convergência na historiografia a respeito de John Dewey no que se refere ao auxilio da construção teórica de Veblen, especificamente sobre os conceitos de hábitos e instituições ${ }^{13}$.

Conforme já destacado, existe um papel extremamente fundamental nos conceitos de instintos, hábitos e instituições, quando se estuda a teoria vebleniana. Essa característica faz-se presente, principalmente, pelo caráter ontológico da teoria do autor que, além de buscar uma perspectiva evolucionária no seu modo de análise, visou também uma maior convergência entre as diferentes áreas do conhecimento humano e social, buscando explicar os comportamentos individuais e suas facetas oriundas da socialização (Veblen, 1898; [1899] 2009).

Vale a menção de que, da mesma maneira que os conceitos de instintos, hábitos e instituições se diferenciam, eles também se complementam. Essa afirmação se fará mais clara quando observarmos o papel atribuído a cada um deles. Afinal, pelo caráter

\footnotetext{
${ }^{13}$ As demais influências de Veblen podem ser vistas como de enriquecimento de perspectiva e análise, como por exemplo, a primeira citada por Edgell \& Tilman (1989), o historicismo alemão.
} 
de influência do pragmatismo clássico em relação aos escritos e Veblen, pode-se notar a observação do comportamento humano como multifacetado, complexo, e inato à socialização. Desse modo, conforme veremos, concede-se a esses conceitos importante papel na construção do individuo como ser social.

\subsection{Os Instintos}

É notável a dificuldade em se precisar o conceito de instintos na teoria de Veblen. Esse reconhecimento pode ser observado de diferentes maneiras, mas em especial em The Instinct of Workmanship and the State of the Industrial Arts, quando o autor comenta" : "[i]t is, of course, not hereby intended to set up or to prescribe a definition of "instinct" at large, but only to indicate as closely as may be what sense is attached to the term as here used" (Veblen, [1914] 2006, p. 4). Porém, mesmo frente a sua dificuldade de conceituação, nota-se que o seu entendimento não apresenta grandes variações nos trabalhos que abordam o tema (Almeida, 2015b; Cavalieri, 2009; Monasterio, 1998).

Já na introdução da supracitada obra, com auxilio de William James e William McDougall, outro importante contribuinte da incipiente psicologia, Veblen estabelece um papel fundamental aos instintos no que se refere à evolução da raça humana, porém salienta que o processo de socialização fez com que estes instintos fossem sendo adaptados à realidade do ser humano, dentro de suas necessidades e objetivos (Veblen, [1914] 2006). Ou seja, até mesmo as características instintivas dos seres humanos apresentam uma seletividade evolucionária (darwiniana). Através desta constatação, Veblen também salienta que ao analisar o comportamento humano contemporâneo, os instintos mostram-se como secundários, ao sentido de que os hábitos seriam muito mais determinantes no comportamento dos indivíduos, principalmente através do caráter convencional e institucional da socialização humana (Veblen, [1914] 2006) ${ }^{15}$. Desse modo, já delatando a inclinação de Veblen a uma noção pragmática-psicológica dos indivíduos e da socialização.

Através do trato de Veblen dado a noção de instintos, podemos amplamente entendê-los como propensões inatas direcionadas a objetivos finais do comportamento humano (Veblen, [1914] 2006). Logo, podemos desde já, observar que os instintos veblenianos divergem da noção biológica, assim como do senso comum. Essa diferenciação deve-se ao caráter único que os seres humanos apresentam sobre essa característica de comportamento. Cavalieri (2009) e Almeida (2015b) destacam que os instintos veblenianos diferem destas noções, pois não corresponderiam a aquelas ações relacionadas a reflexos ou atitudes não deliberadas. Para estes fenômenos do comportamento, Veblen atribui o nome e o conceito de tropismo. Sendo assim, a noção vebleniana de instintos (aplicáveis aos seres humanos) estaria relacionada a uma noção "quase-tropismática" (Veblen, [1914] 2006).

Os instintos humanos não seriam tropismáticos na ótica de Veblen, pois, segundo o autor, é observável no ser humano a sua capacidade de deliberar e raciocinar

\footnotetext{
${ }^{14}$ Monastério (1998), em uma nota de rodapé da página 41, destaca que o próprio Veblen reconheceu nunca ter feito uma definição exata para o seu conceito de instinto. Esta passagem baseia-se no questionamento que Veblen teria feito a respeito deste conceito a Clarence Ayres. Ayres teria pedido desculpa por não se lembrar de uma definição exata. Sorrindo Veblen teria retrucado dizendo que ele não poderia se lembrar, pois ele (Veblen) nunca havia feito tal definição. A referência utilizada por Monastério é Boyles \& Tilman (1993).

${ }^{15}$ Os hábitos e as instituições se farão mais claro no próximo item.
} 
sobre o direcionamento destes, conforme seus anseios e vontades (Veblen, [1914] 2006). Desse modo, os instintos veblenianos seriam direcionamentos comportamentais voltados a satisfação de impulsos internos aos indivíduos que, durante determinado período do processo de evolução humana, podem ter possuído um caráter exógeno em sua composição. Sendo assim, grosso modo, pode-se apresentar aos instintos veblenianos como hábitos fortemente enraizados no comportamento humano (Veblen, [1914] 2006) ${ }^{16}$. Esta noção mostra-se ainda mais evidente quando Veblen ([1914] 2006), expressa seus pensamentos na seguinte passagem ${ }^{17}$ :

The distinctive feature by the mark of which any given instinct is identified is to be found in the particular character of the purpose to which it drives. "Instinct", as contra-distinguished from tropismatic action, involves consciousness and adaptation to an end aimed at (Veblen, [1914] 2006, p. 4).

Dada a noção estabelecida aos instintos na teoria de Veblen, podemos observar um caráter de pluralidade em sua existência. Mais do que isto, também pode-se ressaltar que na perspectiva de atuação desses instintos, Veblen salienta a característica de sobreposição ou então interferência de um instinto sobre o outro. Desse modo, mesmo com a existência de instintos específicos para finalidades específicas, os seus resultados podem ser diferentes dadas as diferentes combinações possíveis entre eles ${ }^{18}$ (Veblen, [1914] 2006). Cavalieri (2009) salienta que este pode ser visto como um ponto de consistência da crítica de Veblen em relação aos escritos neoclássicos que desenhavam uma natureza humana pasteurizada e uniforme. Afinal, mesmo frente a existência de uma essência instintiva nos seres humanos, observa-se que ela pode se constituir e apresentar com variações.

Encaminhando-nos para a finalização da análise e entendimento dessa importante característica da teoria vebleniana, pontua-se que Veblen ([1899] 2009; [1914] 2006) salientou o processo de criação e afloramento instintivo como de longuíssimo prazo, sendo resultado de antigas necessidades de fases remotas da civilização. Segundo Cavalieri (2009), essa característica de criação e "adaptação" dos instintos se faz essencial para diferenciação dos trabalhos de Veblen em relação aos de Spencer e Summer que visavam a construção de um Darwinismo Social. Sendo assim, a perspectiva vebleniana atua no sentido de descreditar a possibilidade de criação e a adesão de instintos humanos em cenário corrente, pois estes seriam o resultado de uma interação de longo prazo entre indivíduos e ambiente. Seria papel dos hábitos e das instituições a variação comportamental de curto prazo (corrente e contemporânea ao tempo desses indivíduos). Ao entendimento destes conceitos dedica-se o próximo item.

\footnotetext{
${ }^{16}$ Ao contrário das habituações e das instituições, os instintos possuem pouca capacidade de alteração, mostrando-se como praticamente os mesmos desde o começo da humanidade. Este destaque é feito por Monastério (1998) com base em Veblen ([1914] 2006).

${ }^{17}$ Em uma nota de rodapé, ao apresentar sua indicação a noção de instintos, Veblen faz menção ao The Principles of Psychology de William James. Nesta menção, James parece deixar em aberto uma possível diferenciação entre tropismo e instintos, na qual Veblen aprofunda suas reflexões e apresenta uma potencial resposta. Na sequencia, Veblen também menciona William Mc Dougall como uma provável fonte/referencia para sua reflexão.

${ }^{18}$ Neste ponto é válido lembrarmos que na perspectiva de Veblen, os instintos não apresentam um correspondente genético único, mas sim são o resultado de diferentes genes (Veblen, [1914] 2006; Monasterio, 1998). Segundo Monastério (1998 apud Dawkins, 1979), a historiografia atual sobre genética e biologia converge com essa perspectiva de Veblen.
} 


\subsection{Os Hábitos e as Instituições}

Enquanto os instintos visam o direcionamento do comportamento humano à um resultado final, cabe aos hábitos o papel de guia e condução deste comportamento. Ou seja, os hábitos condicionam e viabilizam a execução dos instintos, podendo ser observados como códigos de conduta e pensamento. Desde já, observa-se o caráter não trivial das habituações no comportamento humano, pois deve-se a essa característica o papel fundamental do estabelecimento de padrões no pensamento e no comportamento dos indivíduos. Destaca-se que Veblen se utiliza, majoritariamente, das contribuições de John Dewey ao estabelecer sua teorização sobre as habituações e o processo de tomada de decisão. Esta constatação, conforme já observamos, também parece amplamente aceita e entendida por outros autores, como por exemplo, Almeida (2015b) e Monastério (1998). Mas afinal, o que se propõe como hábito na teoria vebleniana e como essa noção se situa no complexo arcabouço teórico do autor?

De modo geral, os hábitos podem ser vislumbrados como modos de se pensar e comportar. Obviamente, devido ao caráter pragmático-psicológico absorvido por Veblen, estes hábitos seriam reflexos de um processo de aprendizado oriundo da socialização humana. Desse modo, as habituações apresentam um caráter de convenção no modo de se comportar. Segundo Veblen ([1914] 2006), essa convencionalização comportamental apresenta-se, substancialmente, como resultado de um processo cumulativo de tradições advindas do passado. Ou seja, o conhecimento e as experiências do passado mostram-se ativas no modo de pensar do presente através da cumulatividade de características comportamentais dos indivíduos. Em última instância, essa cumulatividade de características é responsável pela habituação (Veblen, [1914] 2006).

Desse modo, até então, pode-se observar que o comportamento humano, na perspectiva de Veblen, está associado a dois fatores diferentes, conforme bem destaca Cavalieri (2009, p. 315): "[o] primeiro vem das inclinações instintivas, selecionadas em função dos ambientes, natural e social, em que os individuos estariam inseridos". E, igualmente importante, porém em outra esfera analítica, Cavalieri (2009, p. 316), continua: "[e]m segundo lugar, num nivel mais flexivel porque mais afastado dos atributos propriamente biológicos - ou seja, incrustados na fisiologia humana estariam os hábitos".

Sobre este segundo nível comportamental, atribuído à maior flexibilidade e dinâmica, encontram-se pelo menos duas perspectivas habituais. A primeira delas está associada ao nível dos pensamentos (hábitos de pensamento), e a segunda esta associada à vivência e comportamento dos indivíduos (hábitos de vida). A distinção pode ser vislumbrada pela literalidade de ambas as nomenclaturas. Os hábitos de pensamento atuam a nível cognitivo, auxiliando os indivíduos em suas infinitas deliberações, atuando como mapas mentais ou então como atalhos cognitivos. Já os hábitos de vida atuam no sentido de direcionar os comportamentos do dia-a-dia, normalmente enraizados através da repetição hodierna ${ }^{19}$. Conforme já comentado, ambas as perspectivas habituais são oriundas da socialização e demandam processo de aprendizado, mais uma vez delatando a influência pragmática-psicológica em Thorstein Veblen.

Como inicialmente comentado, os hábitos na perspectiva vebleniana têm o papel fundamental de direcionamento aos objetivos finais dos instintos. Porém, é importante

\footnotetext{
${ }^{19}$ É valido comentar que os hábitos não necessariamente implicam em comportamentos repetitivos, pois podem ser desencadeados uma única vez. O elemento que virá a caracterizar essa repetição seria a resposta ao mesmo ambiento ou um ambiente semelhante ao seu desencadeador.
} 
salientar que durante o processo de habituação pode ocorrer ascensão de objetivos secundários, resultantes dos próprios hábitos. Estes objetivos secundários apresentam-se normalmente, associados a cerimonialismos e demais necessidades de socialização. Afinal, conforme já comentando, e conforme veremos na análise de A Teoria da Classe Ociosa (capítulo 4), as habituações apresentam um papel extremamente importante no processo de adesão e pertencimento a determinados grupos sociais, quais apresentam regras e características específicas, provenientes de processos cumulativos de pensamento e comportamento.

Conforme surge em maior nível e intensidade a coletivização dos hábitos, iniciase um processo de socialização de comportamentos e pensamentos. Exatamente essa característica é a viabilizadora das instituições. Ou seja, pode-se entender as instituições como hábitos de pensamento e de vida que são socialmente compartilhados. Por sua vez, o processo de institucionalização, através de aspectos culturais e convencionais, tem o papel de reforçador de seus hábitos inerentes, tornando-os, cada vez mais, enraizados nos pensamentos e comportamentos dos indivíduos. Ou seja, a institucionalização gera o reforço de hábitos.

Tal enraizamento habitual não deve ser confundido com estática e determinismo. Afinal, conforme já comentado, os hábitos seriam a matriz dinâmica do comportamento humano, sendo atribuídos a eles a capacidade de adaptação do individuo em sua realidade material (Veblen, [1908] 1919). Desse modo, os hábitos atuam de modo a condicionar os comportamentos e pensamentos dos indivíduos, porém não os determinam. Cabe destaque também sobre a característica de desencadeamento dos hábitos, afinal, observa-se a necessidade de síncrono entre aqueles hábitos praticados a nível de pensamentos e a nível de vivência. Sobre tal, Veblen argumenta que os hábitos de vida condicionam os hábitos de pensamento (Veblen, [1906] 1919).

Contata-se ainda que, a existência de diferentes instituições agindo concomitantemente, faz com que as alterações habituais sejam impactantes no comportamento como um todo. Afinal, vislumbrando-se as instituições como uma malha de relações cognitivas e comportamentais, nota-se que a alteração em um elemento institucional, demandaria a readaptação das demais instituições que estariam, direta ou indiretamente, relacionadas com este elemento. Ou seja, nota-se que as instituições possuem capacidade de interferência e sobreposição entre si, tornando sua complexidade e dinâmica, elementos ainda mais importantes no seu entendimento. Através desta noção, destaca-se a uma importante característica relacionada aos hábitos na perspectiva vebleniana: a preservação.

Veblen destaca a "auto preservação" dos hábitos, justificando-a como resultado do caráter conservador do comportamento humano (Veblen, [1899] 2009). Segundo Veblen, o individuo apresentaria a característica de preservação dos seus hábitos de forma indefinida. Somente frente a um cenário em que as circunstâncias o obrigam a uma reformulação habitual ele o fará, porém com enorme relutância. Veblen ([1914] 2006) destaca essa alteração como incômoda, principalmente devido ao caráter de enraizamento cognitivo deste hábito. Afinal, frente a uma mudança necessária em determinada habituação, o individuo apresentará a necessidade do estabelecimento de um novo padrão de pensamento e comportamento. Exatamente com base neste juízo conservador dos hábitos, Veblen estabelece sua explicação sobre a existência e inércia da classe ociosa e não ociosa na sua celebre obra de 1899 .

É observável, então, que as mais diversas habituações são responsáveis pela institucionalização do comportamento humano em socialização. Afinal, as características da sociedade moderna demandam a existência de uma complexa rede institucional, em mais diversos níveis e objetivos. Por essa afirmação ser verdade, não 
raro, os comportamentos institucionalizados são também formalizados em forma de leis, normas, regimentos etc. Desse modo, pode-se observar que as instituições apresentam não só um caráter convencional ao nível coletivo, como também podem ser, comumente, impostas de modo formal aos indivíduos, acarretando o seu descumprimento em penalizações.

Sendo assim, as instituições condicionam o comportamento humano através da socialização dos hábitos. Hábitos que, por sua vez, condicionam, viabilizam e direcionam os instintos. Visando a consolidação destes elementos da teoria vebleniana, Cavalieri (2009, p. 318) destaca-os da seguinte maneira:

\begin{abstract}
Assim, estabelecer-se-iam três níveis formadores do comportamento humano: os instintos, dimensão mais rígida, os hábitos, que consideram a deliberação e são um nível mais individualizado do comportamento; e finalmente, as instituições, hábitos convencionados, arraigados em hábitos de pensar, que conferem à adoção dos comportamentos de acordo com as instituições uma aceitação social. Então, se o critério de valoração social é a adequação dos comportamentos às instituições, estas seriam elementos coercitivos do comportamento humano. As instituições e hábitos, por sua vez, assim como os instintos num nível mais básico, sujeitar-se-iam à seleção num processo evolucionário.
\end{abstract}

É valido salientar que o aspecto habitual - e consequentemente institucional - da teoria vebleniana fora o principal elemento de viabilidade de uma perspectiva nãoteleológica do comportamento humano e social. Afinal, justamente pautado na perspectiva cumulativa de características comportamentais oriunda dos hábitos, é que a teoria vebleniana pôde ser construída aos moldes de uma ciência evolucionária. Exatamente neste ponto torna-se evidente os motivos da inquietação de Veblen em argumentar a necessidade de existência de uma ciência econômica não só evolucionária, mas sim institucional-evolucionária, conforme já expresso na introdução deste trabalho.

Sendo assim, de maneira concisa e geral, os hábitos podem ser entendidos como padrões potenciais de pensamento e comportamento. Quando socializados e convencionalizados, estes padrões assumem o papel de instituição. E, a partir da institucionalização, inicia-se o processo de coerção dos pensamentos e comportamentos gerando o reforço dos hábitos componentes da instituição. Desse modo, o caráter de coletividade e socialização humana, faz com que os indivíduos apresentem uma postura conservadora sobre seus modos de pensar e agir.

\title{
CONSIDERAÇÕES FINAIS
}

Através das contribuições de Thorstein Veblen pode-se vislumbrar uma ampla perspectiva a respeito das instituições. A variação comportamental de curto prazo tem na combinação entre hábitos e instintos uma explicação teórica de potencial utilização em trabalhos aplicados em economia.

Os hábitos são teorizados como modos de se pensar e comportar reflexos de um processo de aprendizado oriundo da socialização humana. Antecipando a ideia de path dependence, Veblen ([1914] 2006) atribui a convencionalização comportamental a processos cumulativos de tradições advindas do passado, ou seja, o conhecimento e as experiências do passado mostram-se ativas no modo de pensar do presente através da cumulatividade de características comportamentais dos indivíduos. 
Veblen oferece uma definição clara de instituições como hábitos de pensamento socialmente compartilhados, bem como um processo de sua constituição. Conforme surge em maior nível e intensidade a coletivização dos hábitos, inicia-se um processo de socialização de comportamentos e pensamentos. Essa característica é a viabilizadora das instituições.

A compreensão de uma certa inércia institucional deriva da interlocução de Veblen com a filosofia psicologista pragmática. Dewey esclareceu o processo de aprendizado como uma relação entre memória e emoções, sendo que através desses fatores, os indivíduos são levados a associações; o caráter habitual dos indivíduos está fortemente ligado a sua necessidade de pertencimento e acolhimento com o grupo social de identificação. Ao destacar a "auto preservação" dos hábitos, justificando-a como resultado do caráter conservador do comportamento, Veblen aporta elementos teóricos que podem auxiliar em trabalhos sobre consolidações de padrões econômicos, tais como os de formação de preços em oligopólio. E esta teorização é afinada com o caráter científico evolucionário, ou seja, o sistema permanece aberto para superação dos padrões convencionados.

\section{REFERÊNCIAS}

Almeida, F. (2015a). The Psychology of Early Institutional Economics: The Instinctive Approach of Thorstein Veblen's Conspicuous Consumer Theory. EconomiA, 226-234.

Almeida, F. (2015b). Revisiting Veblen's "The Theory of The Leisure Class": Pragmatic Philosophy to Understand Conspicuous Consumers's Decision Making. XI Congresso Brasileiro de História Econômica e $12^{a}$ Conferência Internacional de História de Empresas (ABPHE).

Camic, C., \& Hodgson, G. (2011). Essential Writings of Thorstein Veblen. New York: Routledge.

Darwin, C. ([1859] 2014). A Origem das Espécies. São Paulo: Martin Claret.

Dewey, J. ([1886] 1981). Psychology as Philosophic Method. In: J. McDermott, The Philosophy of John Dewey (pp. 116-136). Chicago: The University of Chicago Press.

Dewey, J. ([1934] 1981). Having an Experience. In: J. McDermott, The Philosophy of John Dewey (pp. 554-575). Chicago: The University of Chicago Press.

Dewey, J. ([1939] 1981). Culture and Human Nature. In: J. McDermott, The philosophy of John Dewey (pp. 679-696). Chicago: The University of Chicago Press.

Dugger, W. (1979). The Origins of Thorstein Veblen's Thought. Social Science Quarterly, 424-431. 
Edgell, S., \& Tilman, R. (1989). The Intellectual Antecedents of Thorstein Veblen: A Reappraisal. Journal of Economic Issues, 1003-1026.

Freeman, C. (1987). Technology Policy and Economic Performance: lessons from Japan. London: Frances Pinter.

Hall, L., \& Hitch, J. (1986). A Teoria dos Preços e o Comportamento Empresarial. Rio de Janeiro: Literatura Econômica.

Hamilton, D. (1970). Evolutionary Economics: A Study of Change in Economic Thought. Albuquerque: University of New Mexico Press.

James, W. ([1922] 2009). Pragmatism. Los Angeles: Indo-European Publishing.

Koschmann, T. (2000). The Phsiological an the Social in the Psychologies of Dewey and Thorndike: The Matter of Habit. In: B. \&.-D. Fishman, Fourth International Conference of the Learning Sciences (pp. 314-319). Mahwah: Erlbaum.

Landsman, R. (1957). The Philosophy of Veblen's Economics. Science \& Society, $333-$ 345.

Monasterio, L. (1998). Guia para Veblen: Um Estudo Acerca da Economia Evolucionária. Pelotas: EDUFPEL.

Szapiro, M., Mattos, M., \& Cassiolato, J. (2017). Sistemas de Inovação e Desenvolvimento. In: M. Rapini, \& A. A. Silva, Economia da Ciência, Tecnologia e inovação. Prismas.

Tilman, R. (1998). John Dewey As User and Critic of Thorstein Veblen's Ideas. Journal of the History of Economic Thought, 145-160.

Veblen, T. ([1899] 2009). The Theory of The Leisure Class. New York: Oxford. Coletânia Oxford World's Classics.

Veblen, T. ([1906] 1919). The Place of Science in Modern Civilisation. In: T. Veblen, The Place of Science in Modern Civilisation and Other Essays (pp. 1-31). New York: B.W. Huebsch.

Veblen, T. ([1908] 1919). The Evolution of the Scientific Point of View. In: T. Veblen, The Place of Science in Modern Civilisation (pp. 32-55). New York: B.W. Huebsch.

Veblen, T. ([1914] 2006). The Instinct of Workmanship and The State of the Industrial Arts. New York: Cosimo.

Veblen, T. (1898). Why Is Economics Not an Evolutionary Science? The Quarterly Journal of Economics, 373-397. 
Veblen, T. (1900). The Preconceptions of Economic Science III. The Quarterly Journal of Economics, 240-269.

Webb, J. (2007). Pragmatisms (plural) Part I: Classical Pragmatism and Some Implications for Empirical Inquiry. Journal of Economic Issues, 1036-1086.

Witt, U. (2001). Learning to Consume - A Theory of Wants and the Growth of Demand. Journal of Evolutionary Economics, 23-36.

Witt, U. (2016). The Evolution of Consumption and Its Welfare Effects. Journal of Evolutionary Economics, 1-21. 